\title{
Modeling of tumor radiotherapy with damage and repair processes
}

Jiantao Zhao

Heilongjiang University

Xin Wei

Heilongjiang University

Jianjun Paul Tian ( $\boldsymbol{D}$ jtian@nmsu.edu )

New Mexico State University https://orcid.org/0000-0003-2292-213X

Research

Keywords: Radiotherapy, radiation threshold, damaged cell repair time, Hopf bifurcation, stability

Posted Date: February 23rd, 2021

DOI: https://doi.org/10.21203/rs.3.rs-45714/v2

License: (c) (i) This work is licensed under a Creative Commons Attribution 4.0 International License. Read Full License 


\section{Abstract}

Background: Under irradiation, some cells are damaged permanently and die while some damaged cells can be self-repaired and become normal cells. The same situation happens in tumor radiotherapy. There has been several models to calculate the probability of cell survival after irradiation, and mathematical models for tumor growth to incorporate cell survival probability in radiotherapy. However, there is no detailed study about how both radiation damage process and cell repair process impact outcomes of tumor radiotherapy. This study will focus on impacts of these two processes on tumor radiotherapy. Methods: The study employs mathematical modeling. Based on established mathematical models for tumor growth and irradiation, a functional reaction diffusion system for tumor radiotherapy is proposed. The model has the tumor cell population and damaged tumor cell population, and tracks their movements in the tumor site. The model considers the repair time of damaged tumor cells as a delay parameter. Detailed analysis is conducted while numerical simulations are performed with glioma data. Results: We obtain the radiation threshold which combines the tumor growth rate, the damaged cell death rate, and damaged cell repair rate. The radiation threshold is a decreasing function of radiation dose while the radiation damage rate is a increasing function of radiation dose. The radiation damage rate and repair time determine the outcome of radiotherapy. When the radiation damage rate is greater than the radiation threshold, radiotherapy may destroy the tumor while radiotherapy may control tumor growth and the tumor load decreases as the radiation dose increases when the radiation damage rate is less than the radiation threshold. For both situations, we also observe oscillations of two cell populations occurring from Hopf bifurcations and Turing instability appearing from a large repair time of damaged tumor cells and different cell motilities. Conclusions: The damaged tumor cell repairing process increases the radiation threshold and complicates outcomes of radiotherapy. The medical implication of our results is that radiotherapy may control the tumor growth and the radiation dose can reduce the total tumor load when the damage rate is greater than the radiation threshold, and otherwise, radiotherapy may kill the tumor and the amount of the does not matter.

\section{Full Text}

Due to technical limitations, full-text HTML conversion of this manuscript could not be completed. However, the latest manuscript can be downloaded and accessed as a PDF.

\section{Figures}




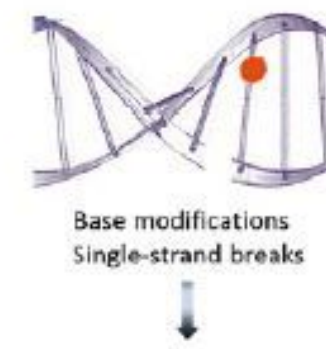

BER

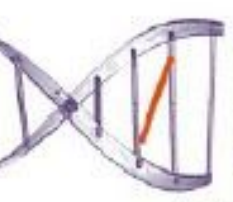

Double-strand breaks Interstrand cross-links

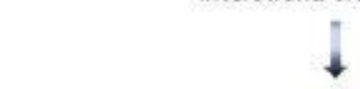

HR

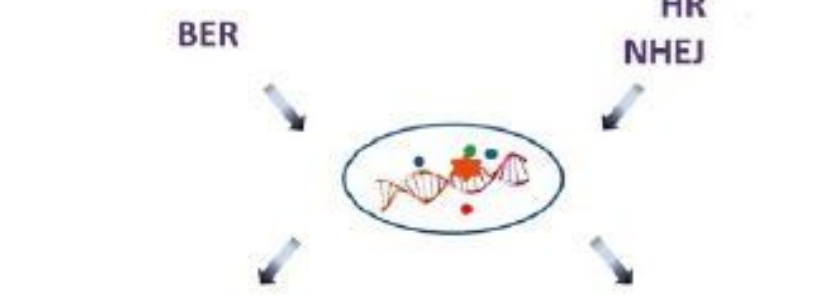

Successful repair

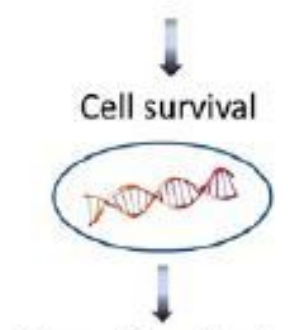

Normal functioning

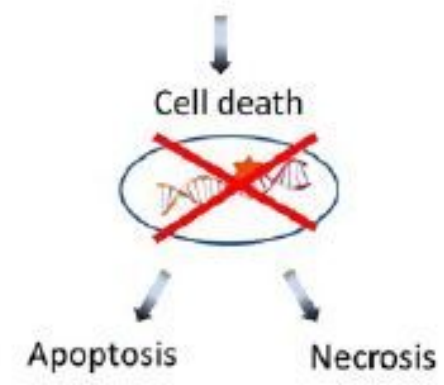

\section{Tumor cells}

Unsuccessful repair

Damaged tumor cells

Cell death

Radiation

Repair

\section{Figure 1}

Left Panel shows cell DNA damage and repair processes in radiation; Right panel shows compartments of the mathematical model.
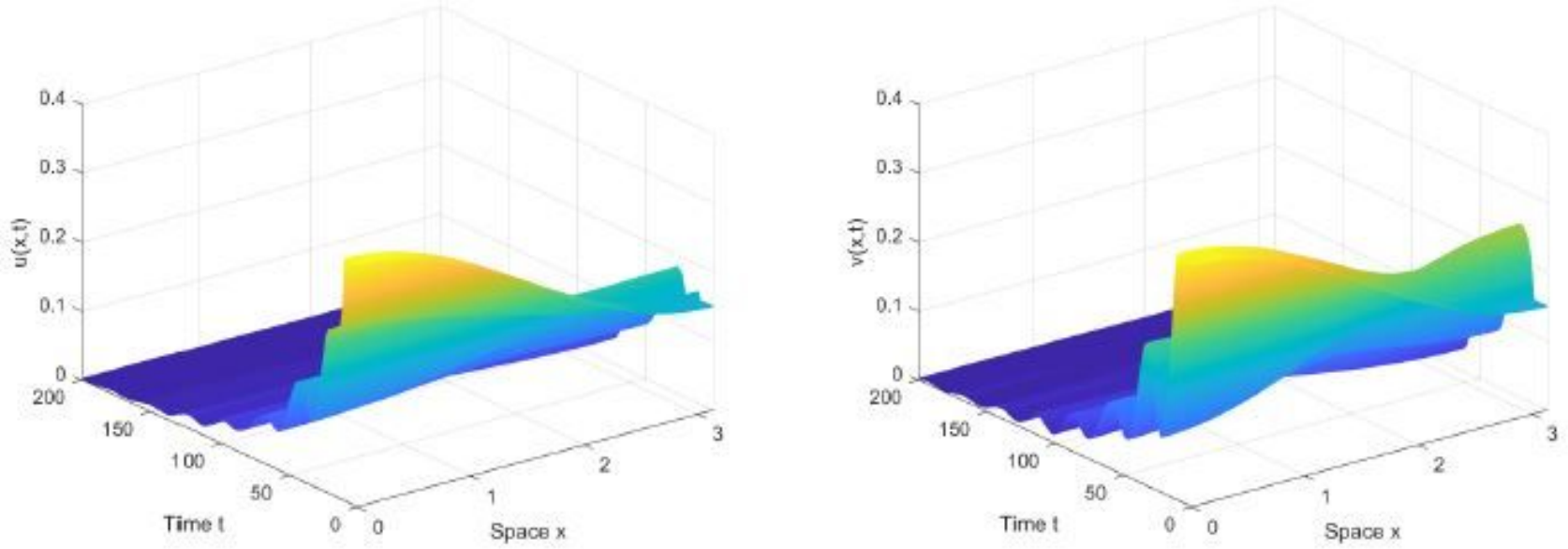

Figure 2 
There exists an asymptotically stable solution, where $r=10<r^{\star}$.
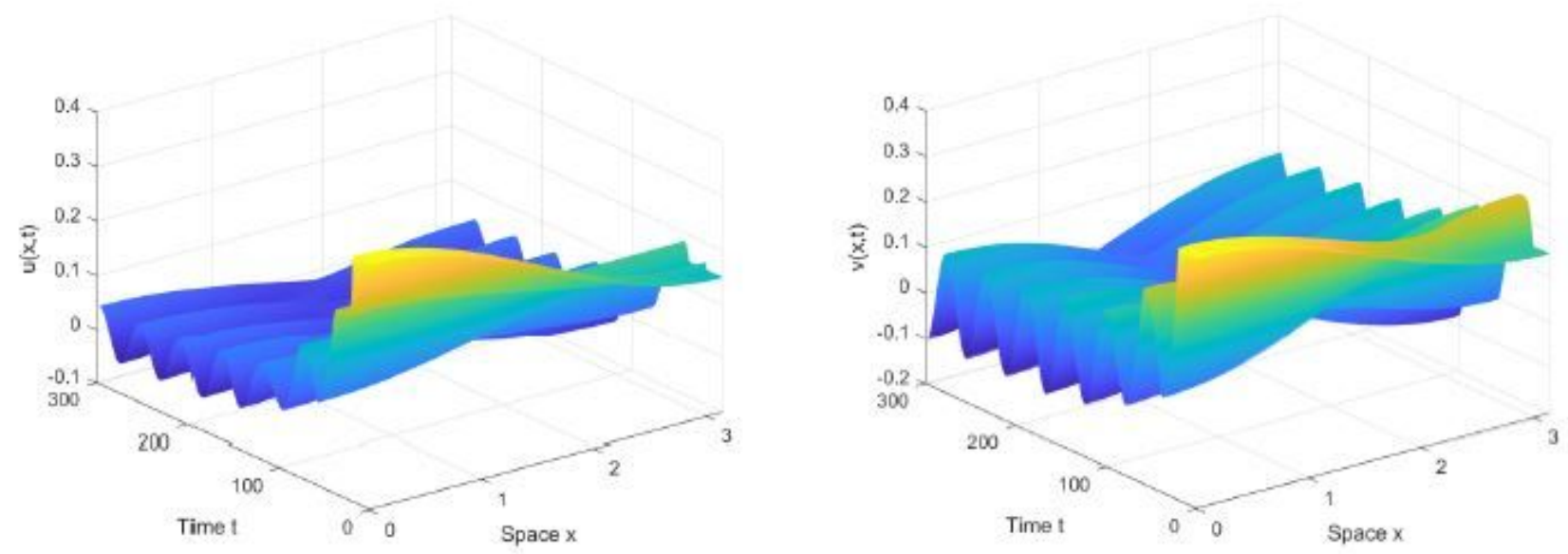

\section{Figure 3}

E0 is Turing unstable, where $r=18>r^{\star}$. We compute
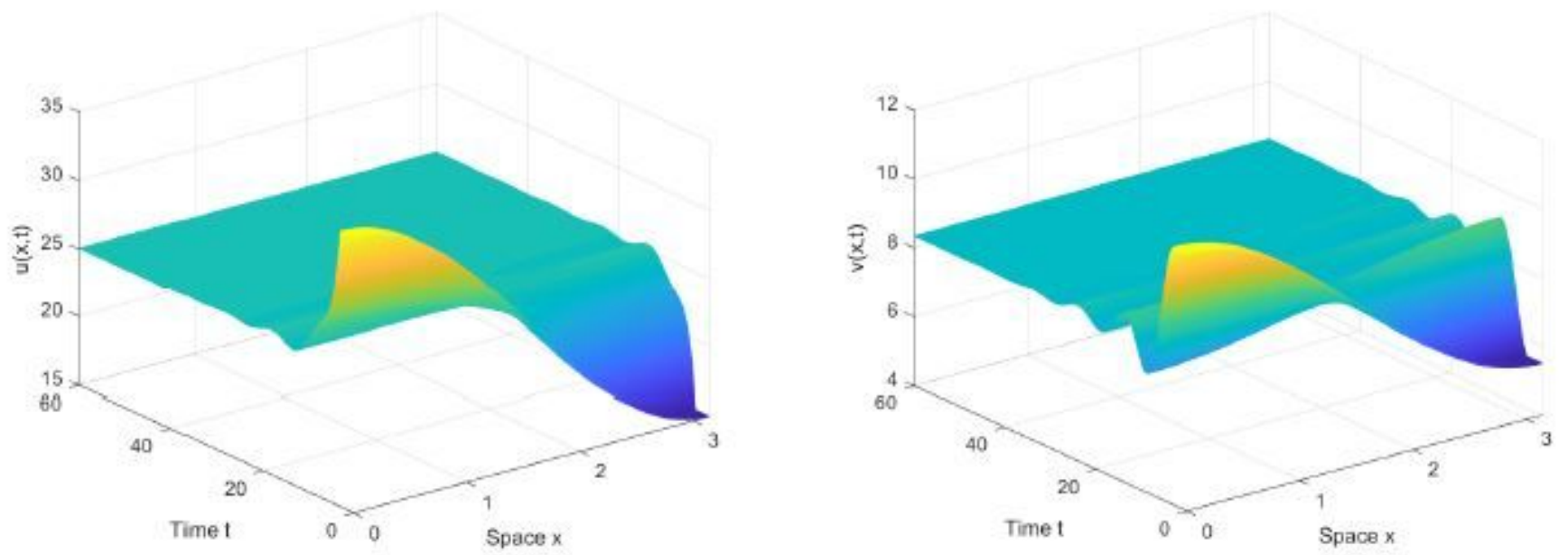

\section{Figure 4}

There steady state $E^{\star}=(25 ; 8: 3333)$ when $r=3<r^{*}$. 

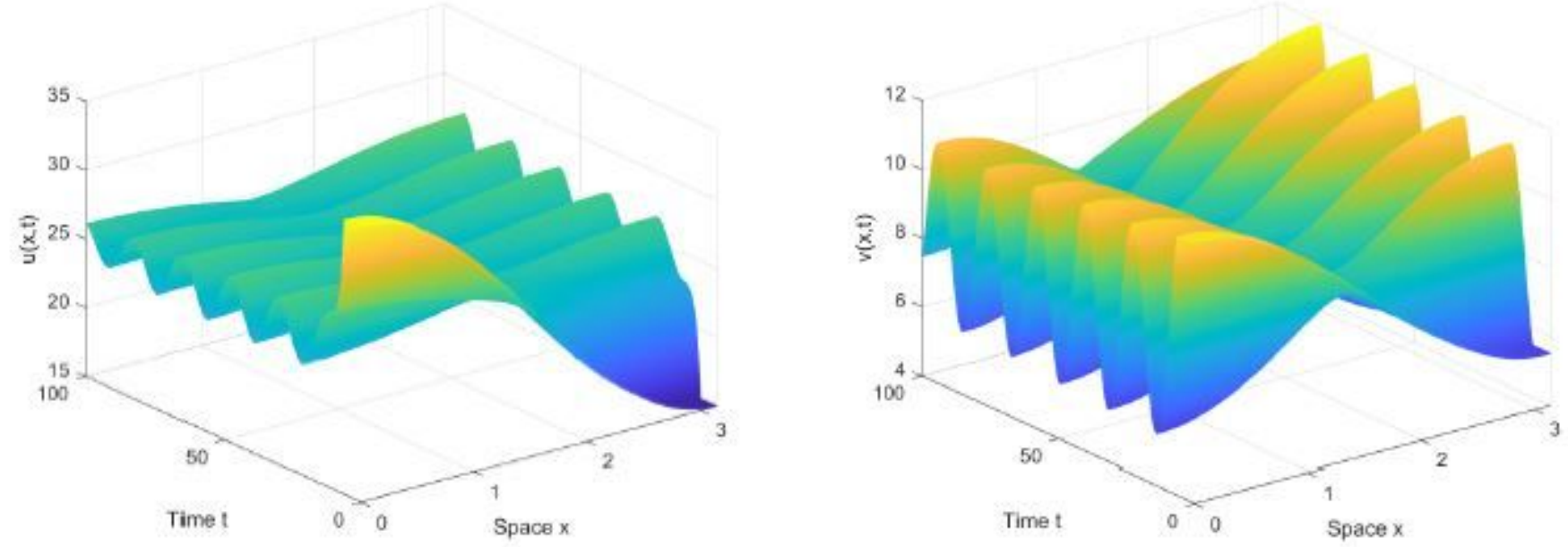

Figure 5

There exists an orbitally stable periodic solution when $r=6>\sim r *$.

\section{Supplementary Files}

This is a list of supplementary files associated with this preprint. Click to download.

- SupplementaryDocuments.docx 